\title{
THE REAL MECHANISM OF TECHNOLOGY TRANSFER
}

$\mathrm{S}$

everal things about the recent discussions of "biotechnology transfer" have disturbed us. All the talk of late has been of things, not of people, of tools, not of the craft of using them. Both elements, the human and the material, are vital to any technology. Yet biotechnology, tied so closely to the lab bench, is mainly transported not in crates of equipment but in the minds of men and women. Circumscribing the movements of objects, particularly uncommon objects, is a straightforward affair, if tedious and sometimes futile. Circumscribing the motions of people or the flow of learning reeks of tyranny.

Every nation we can think of (and every region, and every corporation or institute) seems now to want to seize the lead in biotechnology and hold it. Each tries to balance the biotech transfer equation (compounded of science, money, freedom, and secrecy) in its favor.

But biotechnology is a small community. By one estimate, there are fewer than 30,000 working biotechnologists in the world, in industry and academia together (Nature 308:572; 1984). We have lived in rural hamlets more populous. A certain small-town atmosphere is inescapable: everybody seems to know a little bit about everybody else's business; judgments are frequent, harsh, and tempered with a dash of familial loyalty.

It was once possible for the United States and Great Britain to concentrate a similarly small community into a series of small towns-in Los Alamos, Hanford, and the Tennessee Valley - and thus briefly control a new technology. And while the Allies tried to interdict high technology supplies like heavy water, their greatest efforts were devoted to supervising publication, talk, and education.

\section{What Customs Withholds, Academe Offers}

Even now, the U.S. Departments of Defense and Commerce are battling it out to see which agency will ultimately control the export of high-technology equipment. And French President François Mitterrand specifically protested the U.S.'s restrictive policies on high-tech exports, modestly jarring the summer's summit meeting in England.

Meanwhile, the U.S. continues to welcome thousands of foreign students and researchers. In 1983, the National Institutes of Health alone sponsored more than 800 visiting scientists under its "visiting program," according to the Office of Technology Assessment's (OTA) Commercial Biotechnology. Far greater are the numbers of foreign students who come to the United States either on their own or under government sponsorship. According to The Wall Street Journal, mainland China alone has sent more than 9,000 scientists to study in the U.S over the past fiveand-a-half years. A much-publicized statistic tells the story: in 1981, more than half of those receiving Ph.D.s in engineering from U.S. institutions were foreigners.

The United States is not operating a vast international science give-away, however. We have no ready statistics on the number of foreign students who elect to stay in the U.S. We suspect that both the number and the benefit to the country are large. Industry's voracious and still unsatisfied appetite for scientists and engineers has left gaps on university faculties.

Different countries have different trade balances in international scholarly traffic. The Japanese send a great many of their scientists and engineers abroad to study, to build on the country's established, but narrow, research base in the practical science of microbial physiology, according to Commercial Biotechnology. Japanese companies then aggressively recruit those with foreign training. The rate of return on dollars invested (and the rate of return of traveling scientists) is presumably quite high.

The United Kingdom, which boasts one of the world's greatest resources in the vital disciplines of bioprocess engineering, loses some 30 biotechnologists a year-out of a total population of 2,000-to more attractive opportunities abroad, mainly in the U.S.

Other countries or regions are relatively poor in established pools of biotechnologists, and look to regional institutes to lure the learned. This was, of course, one of the prime motives in the debates over a location for the UNIDO International Center for Genetic Engineering and Biotechnology. This "magnet" approach has also prompted the founding of such institutions as the Instituto Internacional de Estudios Avanzados (IDEA, Caracas), which has, over the past three years, trained some 1245 students, most of them from the third world, in courses taught primarily by faculty from the United States and Europe.

\section{The Frustrations of Hobbled Science}

We frequently hear admiring comments about the quality and commitment of the mainland Chinese working in American laboratories; almost as frequently, we hear warm predictions of a Chinese biotechnological revolution in the mid-1990s. But knowledge alone, even knowledge coupled with dedication, cannot make that revolution happen without some of the tools of the trade. The Wall Street Journal has told an especially poignant story of one Chinese researcher who returned home from the United States, only to find that "for a large part of his day he does nothing more creative than fill out orders for supplies, go to meetings, and even wash bottles. 'I spend half of my research time doing things that could be done by someone with a junior-high-school education,' the molecular biologist says. 'I could do one experiment a week in the U.S.; here, I can barely do one a semester.' "

We suggest that recent efforts, by the United States and others, to control technology transfer by restricting the export of equipment is, if not equivalent to barring the barn door after the horse has bolted, then tantamount to hobbling the horse while leaving the doors wide open. The beast will go wherever it wants; it just may take a little more time getting to some places than to others.

-Douglas McCormick 